\title{
METODE NUMERIK UNTUK MENENTUKAN HARGA OPSI DENGAN MODEL VOLATILITAS LELAND
}

\author{
Arsyad L ${ }^{1}$, Donny Citra Lesmana ${ }^{2}$, Endar Hasafah Nugrahani ${ }^{3}$ \\ 1,2,3 IAIN Palopo, IPB University, IPB University \\ 1,2,3 Jalan Agatis Balandai, Palopo; Jalan Meranti, Bogor 16680, Indonesia; Jalan Meranti, \\ Bogor 16680, Indonesia \\ E-mail : arsyad@iainpalopo.ac.id ${ }^{1}$, donny.lesmana@graduate.uwa.edu.au ${ }^{2}$ \\ e_nugrahani@ipb.ac.id ${ }^{3}$
}

\begin{abstract}
Option price under transaction cost with leland volatility model is the solution of a non linear diferential equations. To solve this equation used numerical methods based on an upwind finite difference for spatial discretization as well as the use of explicit and implicit methods for discretizing time-stepping. upwind finite difference method with explicit time-stepping scheme proved to be unstable so as not konvegen. While the use of implicit time-stepping scheme is proved monotonous, consistent and stable so that converge to the viscosity solution.
\end{abstract}

Keywords: option value, leland volatility model, upwind finite difference methode, convergence, nonlinear partial difeferencial equation.

\section{PENDAHULUAN / INTRODUCTION}

Hal terpenting dalam perdagangan opsi adalah penentuan harga jual yang optimal. Teori penentuan harga opsi telah dikembangkan pada tahun 1973 oleh Fisher Black dan Myron Scholes yang berhasil merumuskan masalah penentuan harga opsi ke dalam bentuk persamaan diferensial parsial (PDP) Black Scholes.

$$
-W_{t}=\frac{1}{2} \sigma_{0}^{2} S^{2} W_{S S}+r S W_{S}-r W
$$

dimana $W$ adalah harga opsi, $S$ adalah harga saham, $\sigma$ adalah volatilitas harga saham, $r$ adalah suku bunga bebas risiko, dan $t$ adalah waktu (Black\& Scholes 1973) .

Model Black scholes menggunakan beberapa asumsi, yang salah satunya adalah tidak terdapat biaya transaksi. Model Black scholes tidak relevan sebab pada kenyataannya terdapat biaya transaksi di pasar saham. Dengan memasukkan biaya transaksi ke dalam model, Leland menunjukkan bahwa persaman diferensial parsial (PDP) Black Scholes berubah menjadi persamaan diferensial parsial taklinear. Selanjutnya dengan mengasumsikan biaya transaksi proporsional dengan nilai uang dari aset yang dijual atau dibeli, Leland memodifikasi persamaan diferensial parsial (PDP) Black Scholes (1) menjadi persamaan diferensial parsial (PDP) Black Scholes taklinear

$$
-W_{t}=\frac{\sigma^{2}\left(w_{S S}\right)}{2} S^{2} W_{S S}+r S W_{S}-r W
$$

dengan volatitas termodifikasi sebagai berikut 


$$
\sigma^{2}=\sigma_{0}^{2}\left(1+\sqrt{\frac{2}{\pi}}\left(\frac{k}{\sigma_{0}^{2} \sqrt{\delta t}}\right) \operatorname{Sign}\left(W_{s s}\right)\right),
$$

di mana $\sigma$ adalah volatilitas termodifikasi, $k$ adalah biaya transaksi dan $\delta t$ adalah periode transaksi (Leland 1985).

Dengan mentransformasi waktu $\tau=T$ - $t$ persamaan (2) berubah menjadi

$$
W_{\tau}=\frac{\sigma^{2}}{2} S^{2} W_{S S}+r S W_{S}-r W
$$

PDP tak linier tersebut tidak mempunyai solusi analitik sehingga dibutuhkan pendekatan metode numerik untuk menentukan solusi hampirannya. Beberapa pendekatan secara numerik dapat dilakukan untuk menentukan harga opsiyaitu dengan metode beda hingga (finite difference method), metode volume hingga (finite volume method), metode elemen hingga dan lain-lain. Pada penelitian ini akan dikembangkan metode beda hingga upwind.

\section{TINJAUAN TEORITIK / LITERATURE REVIEW}

Metode beda hingga upwind adalah suatu metode numerik untuk menyelesaikan persamaan diferensial parsial taklinear mengkombinasikan metode beda hingga maju dan beda hingga mundur untuk diskretisasi ruang ( harga saham).

Persamaan Black-Scholes taklinear akan diaproksimasi dengan diskretisasi harga dan waktu. Untuk diskretisasi harga, misalkan $I=\left(0, S_{\max }\right)$ dibagi menjadi $M$ sub-interval, dimana

$$
I_{i}=\left(S_{i}, S_{i+1}\right), \quad i=0,1, \ldots, M-1
$$

dengan $0=S_{0}<S_{1}<\cdots<S_{M}=S_{\max }$, dan untuk setiap $i=0,1, \ldots ., M-1$ dimisalkan $h=S_{i+1}-S_{i}$. Untuk diskretisasi waktu, misalkan $\tau=(0, T)$ dibagi menjadi $N$ sub-interval, dimana

$$
\tau_{n}=\left(\tau_{n}, \tau_{n+1}\right), \quad n=0,1, \ldots, N-1
$$

dengan $0=\tau_{0}<\tau_{1}<\cdots<\tau_{n}=T$ dan untuk setiap $n=0,1, \ldots, N-1$ dimisalkan $\Delta \tau=$ $\tau_{n+1}-\tau_{n}$.

Aproksimasi turunan parsial pertama dan kedua diperoleh dari ekspansi deret Taylor, seperti berikut ini. Untuk sembarang $W^{n}=\left(W_{0}^{n}, W_{1}^{n}, \ldots, W_{M}^{n}\right)^{\prime}$ dan $W_{i}=\left(W_{i}^{0}, W_{i}^{1}, \ldots, W_{i}^{N}\right)^{\prime}$ dengan $i=0,1, \ldots, M$ dan $n=0,1, \ldots, N$, didefinisikan turunan pertama dan turunan kedua mengikuti operator beda hingga dengan mengunakan skema eksplisit dan implisit (Lesmana 2013).

\section{Bentuk Skema Eksplisit}

Pada skema eksplisit, variabel pada waktu $n+1$ dihitung berdasarkan variabel pada waktu $n$ yang sudah diketahui. sehingga operator beda hingga yang digunakan adalah sebagai berikut :

$$
\begin{aligned}
\left(\delta_{\tau} W_{i}\right)(n) & =\frac{W_{i}^{n+1}-W_{i}^{n}}{\Delta \tau_{n}}, \\
\left(\delta_{S}^{+} W^{n}\right)(i) & =\frac{W_{i+1}^{n}-W_{i}^{n}}{h}, \quad\left(\delta_{S}^{-} W^{n}\right)(i)=\frac{W_{i}^{n}-W_{i-1}^{n}}{h}, \\
\left(\delta_{S S} W^{n}\right)(i) & =\frac{\left(\delta_{S}^{+} W^{n}\right)(i)-\left(\delta_{S}^{-} W^{n}\right)(i)}{2 h / 2} \\
& =\frac{W_{i-1}^{n}-2 W_{i}^{n}+W_{i+1}^{n}}{h^{2}} .
\end{aligned}
$$




\section{Bentuk Skema Implisit}

Pada skema implisit variabel pada waktu $n+1$ dihitung berdasarkan variabel pada waktu $n$ yang sudah diketahui serta variavel pada waktu $n+1$ yang belum diketahui. Sehingga, operator beda hingga yang digunakan adalah sebagai berikut

$$
\begin{aligned}
\left(\delta_{\tau} W_{i}\right)(n) & =\frac{W_{i}^{n+1}-W_{i}^{n}}{\Delta \tau_{n}}, \\
\left(\delta_{S}^{+} W^{n+1}\right)(i) & =\frac{W_{i+1}^{n+1}-W_{i}^{n+1}}{h}, \quad\left(\delta_{S}^{-} W^{n}\right)(i)=\frac{W_{i}^{n+1}-W_{i-1}^{n+1}}{h} \\
\left(\delta_{S S} W^{n+1}\right)(i) & =\frac{\left(\delta_{S}^{+} W^{n+1}\right)(i)-\left(\delta_{S}^{-} W^{n+1}\right)(i)}{2 h / 2} \\
& =\frac{W_{i-1}^{n+1}-2 W_{i}^{n+1}+W_{i+1}^{n+1}}{h^{2}}
\end{aligned}
$$

\section{METODE PENELITIAN / METHODS}

Penelitian ini di laksanakan dengan menggunakan metode studi literatur, yaitu dengan mengumpulkan teori dan data dari literatur terdahulu yang relefan dengan penelitian ini.

Adapun langkah-langkah yang akan dilakukan dalam penelitian ini adalah:

1. Melakukan diskretisasi untuk model Black-Scholes taklinear dengan diskretisasi beda hingga upwinduntuk diskretisasi ruang ( harga saham) serta diskretisasi eksplisit dan implisit untuk dikritisasi waktu.

2. Memeriksa kekonvergenan skema numerik metode beda hingga upwind.

3. Melakukan simulasi numerik untuk menunjukkan akurasi dari metode diskretisasi beda hingga upwind.

\section{HASIL DAN PEMBAHASAN / DISCUSSION}

Untuk menyelesaikan suatu permasalahan persamaan diferensial parsial dengan menggunakan metode beda hingga upwind ada beberapa hal yang perlu diperhatikan, yaitu kondisi syarat awal dan syarat batas, diskretisasi persamaan tersebut, serta kekonvergenan dari skema beda hinggaupwind.

\section{Syarat Awal dan Syarat Batas.}

Syarat batas untuk persamaaan Black-Scholes taklinear adalah sebagai berikut:

$$
\begin{aligned}
U(S, 0) & =g_{1}(S), & & S \in\left(0, S_{\max }\right), \\
U(0, \tau) & =g_{2}(\tau), & & \tau \in(0, T], \\
U\left(S_{\max }, \tau\right) & =g_{3}(\tau), & & \tau \in(0, T],
\end{aligned}
$$

dengan $g_{1}, g_{2}$, dan $g_{3}$ adalah suatu fungsi yang diberikan dengan $g_{1}(0)=g_{2}(0)$ dan $g_{1}\left(S_{\max }\right)=g_{3}(0)$. Fungsi $g_{1}, g_{2}$, dan $g_{3}$ dipilih berdasarkan tipe opsi, di mana dalam penelitiaan ini opsi yang akan digunakan adalah opsi eropa yaitu opsi Call Vanilla, PutVanilla, Butterfly, dan Cash or Nothing (CoN) dengan syarat awal dan syarat batas sebagai berikut:

$$
g_{1}=\left\{\begin{array}{c}
\max (S-K, 0) \text { untuk call } \\
\max (K-S, 0) \text { untuk put } \\
\max \left(S-K_{1}, 0-2 \max \left(\mathrm{S}-\mathrm{K}_{2}, 0\right)+\max \left(\mathrm{S}-\mathrm{K}_{3}, 0\right)\right) \\
B \times \mathcal{H}(S-K) \text { untuk CoN }
\end{array} \quad\right. \text { untuk butterfly }
$$


$g_{2}=\left\{\begin{array}{cl}0 & \text { untuk call } \\ K e^{-r \tau} & \text { untuk put } \\ 0 & \text { untuk butterfly } \\ 0 & \text { untuk CoN }\end{array}\right.$

$g_{3}= \begin{cases}S_{\max }-K e^{-r \tau} & \text { untuk call } \\ 0 & \text { untuk put } \\ 0 & \text { untuk butterfly } \\ \quad B e^{-r \tau} & \text { untuk CoN }\end{cases}$

dengan $\mathcal{H}$ adalah fungsi heaviside, $B$ adalah konstanta, $K, K_{1}, K_{2}$, dan $K_{3}$ adalah harga stike.

\section{Diskretisasi Eksplisit}

Persamaan Black-Scholes taklinear (4) diaproksimasi dengan menggunakan operator (5-7) dan dengan mengaplikasikan metode beda hingga upwindserta diskretisasi eksplisit terhadap waktu menjadi sebagai berikut:

$$
\begin{gathered}
\delta_{\tau} U_{i}(j)-\frac{1}{2} \sigma^{2}\left(\left(\delta_{S S} U^{j}\right)(i)\right) S_{i}^{2}\left(\delta_{S S} U^{j}\right)(i)-\left(\frac{1+\operatorname{sign}(r)}{2}\right) r S_{i}\left(\delta_{S}^{+} U^{j}\right)(i)- \\
\left(\frac{1-\operatorname{sign}(r)}{2}\right) r S_{i}\left(\delta_{S}^{-} U^{j}\right)(i)+r U_{i}^{j}=0 .
\end{gathered}
$$

Dalam model volatilitas leland diketahui bahwa nilai $r>0$, sehingga persamaan di atas dapat ditulis menjadi:

$$
\delta_{\tau} U_{i}(j)-\frac{1}{2} \sigma^{2}\left(\left(\delta_{S S} U^{j}\right)(i)\right) S_{i}^{2}\left(\delta_{S S} U^{j}\right)(i)-r S_{i}\left(\delta_{S}^{+} U^{j}\right)(i)+r U_{i}^{j}=0
$$

Selanjutnya, diperoleh:

$$
\begin{gathered}
\frac{U_{i}^{j+1}-U_{i}^{j}}{\Delta \tau}-\frac{1}{2} \sigma^{2}\left(\left(\delta_{S S} U^{j}\right)(i)\right) S_{i}^{2}\left(\frac{U_{i-1}^{j}-2 U_{i}^{j}+U_{i+1}^{j}}{h^{2}}\right)-r S_{i}\left(\frac{U_{i+1}^{j}-U_{i}^{j}}{h}\right)+r U_{i}^{j}=0, \\
U_{i}^{j+1}=\Delta \tau_{j} \frac{1}{2} \sigma^{2}\left(\left(\delta_{S S} U^{j}\right)(i)\right) S_{i}^{2}\left(\frac{U_{i-1}^{j}-2 U_{i}^{j}+U_{i+1}^{j}}{h^{2}}\right)+\Delta \tau_{j} r S_{i}\left(\frac{U_{i+1}^{j}-U_{i}^{j}}{h}\right) \\
+(1-\Delta \tau r) U_{i}^{j} .
\end{gathered}
$$

Persamaan (17) dapat disederhanakan menjadi bentuk berikut:

$U_{i}^{j+1}=\alpha_{i}^{j}\left(U^{j}\right) U_{i-1}^{j}+\beta_{i}^{j}\left(U^{j}\right) U_{i}^{j}+\gamma_{i}^{j}\left(U^{j}\right) U_{i+1}^{j}$,

untuk $i=1, \ldots, M-1$ dan $j=1, \ldots, N-1$, di mana:

$\alpha_{i}^{j}\left(U^{j}\right)=\frac{1}{h^{2}} \Delta \tau_{j} \frac{1}{2} \sigma^{2}\left(\left(\delta_{S S} U^{j}\right)(i)\right) S_{i}^{2}$,

$\beta_{i}^{j}\left(U^{j}\right)=1-r \Delta \tau_{j}-\frac{1}{h} \Delta \tau_{j} r S_{i}^{2}-\frac{1}{h^{2}} \Delta \tau_{j} \sigma^{2}\left(\left(\delta_{S S} U^{j}\right)(i)\right) S_{i}^{2}$,

$\gamma_{i}^{j}\left(U^{j}\right)=\frac{1}{h} \Delta \tau_{j} r S_{i}^{2}+\frac{1}{h^{2}} \Delta \tau_{j} \sigma^{2}\left(\left(\delta_{S S} U^{j}\right)(i)\right) S_{i}^{2}$.

untuk $i=1,2, \ldots, M-1$ dan $j=0,1, \ldots, N$, sehingga persamaan (18) dapat dituliskan dalam bentuk notasi matriks berikut

$\widehat{U}^{j+1}=A^{j}\left(U^{j}\right) \widehat{U}^{j}+B^{j}$,

untuk $j=1,2, \ldots, N$, di mana 


$$
A^{j}\left(U^{j}\right)=\left[\begin{array}{ccccccc}
\beta_{1}^{j} & \gamma_{1}^{j} & 0 & \ldots & 0 & 0 & 0 \\
\alpha_{2}^{j} & \beta_{2}^{j} & \gamma_{2}^{j} & \ldots & 0 & 0 & 0 \\
0 & \alpha_{3}^{j} & \beta_{3}^{j} & \ldots & 0 & 0 & 0 \\
\vdots & \vdots & \vdots & \ddots & \vdots & \vdots & \vdots \\
0 & 0 & 0 & \ldots & \beta_{M-3}^{j} & \gamma_{M-3}^{j} & 0 \\
0 & 0 & 0 & \ldots & \alpha_{M-2}^{j} & \beta_{M-2}^{j} & \gamma_{M-2}^{j} \\
0 & 0 & 0 & \ldots & 0 & \alpha_{M-1}^{j} & \beta_{M-1}^{j}
\end{array}\right]
$$

$\widehat{U}^{k}=\left(U_{1}^{k}, U_{2}^{k}, \ldots, U_{M-1}^{k}\right)^{\prime}$ untuk $k=j, j+1$

$B^{j}=\left(\alpha_{1}^{j} U_{0}^{j}, 0, \ldots, 0, \gamma_{M-1}^{j} U_{N}^{j}\right)$ ' $^{\prime}$

\section{Diskretisasi Implisit}

Dengan cara yang sama pada diskritsisasi eksplisit, dengan menggunakan diskretisasi skema implisit terhadap waktu, persamaan Black-Scholes taklinear (4) diaproksimasi mengikuti bentuk metode beda hingga upwindmenggunakan operator (8-10) menjadi seperti berikut:

$\alpha_{i}^{n+1}\left(U^{n+1}\right) U_{i-1}^{n+1}+\beta_{i}^{n+1}\left(U^{n+1}\right) U_{i}^{n+1}+\gamma_{i}^{n+1}\left(U^{n+1}\right) U_{i+1}^{n+1}=\frac{1}{\Delta \tau_{n}} U_{i}^{n}$,

untuk $i=1, \ldots, M-1$ dan $n=1, \ldots, N-1$, di mana:

$\alpha_{i}^{n+1}\left(U^{n+1}\right)=-\frac{1}{2 h^{2}} \sigma^{2}\left(\delta_{S S} U^{n+1}\right)(i) S_{i}^{2}$,

$\beta_{i}^{n+1}\left(U^{n+1}\right)=\frac{1}{\Delta \tau_{n}}+\frac{1}{h^{2}} \sigma^{2}\left(\delta_{S S} U^{n+1}\right)(i) S_{i}^{2}+\frac{r S_{i}}{h}+r$,

$\gamma_{i}^{n+1}\left(U^{n+1}\right)=-\frac{1}{2 h^{2}} \sigma^{2}\left(\delta_{S S} U^{n+1}\right)(i) S_{i}^{2}-\frac{r S_{i}}{h}$.

Berdasarkan syarat batas (11-13), didefinisikan syarat awal dan syarat batas untuk persamaan (26) adalah sebagai berikut

$$
U_{i}^{0}=g_{1}\left(S_{i}\right) \quad U_{0}^{n}=g_{2}\left(\tau_{n}\right) \quad U_{M}^{n}=g_{3}\left(\tau_{n}\right)
$$

untuk $i=1,2, \ldots, M-1$ dan $n=1, \ldots, N$, sehingga persamaan (26) dapat dituliskan dalam bentuk matriks berikut

$A^{n+1}\left(U^{n+1}\right) \widehat{U}^{n+1}=\frac{1}{\Delta \tau_{n}} \widehat{U}^{n}+B^{n+1}$,

untuk $n=1, \ldots, N-1$, di mana

$$
A^{n+1}\left(U^{n+1}\right)=\left[\begin{array}{ccccccc}
\beta_{1}^{n+1} & \gamma_{1}^{n+1} & 0 & \ldots & 0 & 0 & 0 \\
\alpha_{2}^{n+1} & \beta_{2}^{n+1} & \gamma_{2}^{n+1} & \ldots & 0 & 0 & 0 \\
0 & \alpha_{3}^{n+1} & \beta_{3}^{n+1} & \ldots & 0 & 0 & 0 \\
\vdots & \vdots & \vdots & \ddots & \vdots & \vdots & \vdots \\
0 & 0 & 0 & \ldots & \beta_{M-3}^{n+1} & \gamma_{M-3}^{n+1} & 0 \\
0 & 0 & 0 & \ldots & \alpha_{M-2}^{n+1} & \beta_{M-2}^{n+1} & \gamma_{M-2}^{n+1} \\
0 & 0 & 0 & \ldots & 0 & \alpha_{M-1}^{n+1} & \beta_{M-1}^{n+1}
\end{array}\right]
$$

$\widehat{U}^{k}=\left(U_{1}^{k}, U_{2}^{k}, \ldots, U_{M-1}^{k}\right)^{\prime}$ untuk $k=n, n+1$ 
$B^{n+1}=\left(-\alpha_{1}^{n+1} U_{0}^{n+1}, 0, \ldots, 0,-\gamma_{M-1}^{n+1} U_{N}^{n+1}\right)^{\prime}$

\section{Teorema 1. Matriks-M}

Untuk sembarang $n=0,1, \ldots, N, A^{n}=\left(A_{i j}^{n}\right)$ adalah suatu matriks-M untuk $U^{n}$ yang diberikan.

\section{Kekonvergenan dari Skema Numerik}

Barles (1997) telah menunjukkan bahwa metode numerik dikatakan konvergen ke solusi viskositas jika metode tersebut terbukti konsisten, stabil dan monoton. Pada bagian ini akan ditunjukkan bahwa skema diskretisasi metode beda hingga upwind yang digunakan memenuhi syarat konvergen tersebut.

Untuk $1 \leq i \leq M-1$ dan $0 \leq n \leq N-1$ didefinisikan suatu fungsi $F_{i}^{n+1}$

dimana

$$
\begin{gathered}
F_{i}^{n+1}=\left(-\frac{r S_{i}}{h}\right) U_{i+1}^{n+1}+\left(\frac{1}{\Delta \tau_{n}}+\frac{r S_{i}}{h}+r\right) U_{i}^{n+1}-\frac{U_{i}^{n}}{\Delta \tau_{n}} \\
-\frac{1}{h^{2}} \sigma^{2}\left(\left(\Gamma^{n+1}\right)(i)\right)\left(\Gamma^{n+1}\right)(i) .
\end{gathered}
$$

\section{Teorema 2. Kemonotonan}

Skema diskretisasi pada persamaan (26) monoton yaitu untuk sembarang $\varepsilon>0$ dan $i=$ $1,2, \ldots, M-1$,

$Z_{i}^{j+1}\left(U_{i}^{j+1}, U_{i+1}^{j+1}+\varepsilon, U_{i-1}^{j+1}+\varepsilon, U_{i}^{j}+\varepsilon\right) \leq Z_{i}^{j+1}\left(U_{i}^{j+1}, U_{i+1}^{j+1}, U_{i-1}^{j+1}, U_{i}^{j}\right)$

dan

$$
Z_{i}^{j+1}\left(U_{i}^{j+1}, U_{i+1}^{j+1}, U_{i-1}^{j+1}, U_{i}^{j}\right) \geq Z_{i}^{j+1}\left(U_{i}^{j+1}, U_{i+1}^{j+1}+\varepsilon, U_{i-1}^{j+1}+\varepsilon, U_{i}^{j}+\varepsilon\right)
$$

\section{Teorema 3. Kestabilan}

Untuk setiap $n=0,1, \ldots, N-1$, misalkan $U^{n+1}=\left(U_{0}^{n+1},\left(\widehat{U}^{n+1}\right)^{\prime}, U_{M}^{n+1}\right)^{\prime}$ di mana $\widehat{U}^{n+1}$ adalah solusi dari (31), maka $U^{n+1}$ memenuhi

$$
\left\|U^{n+1}\right\|_{\infty} \leq \max \left\{\left\|g_{1}\right\|_{\infty},\left\|g_{2}\right\|_{\infty},\left\|g_{3}\right\|_{\infty}\right\}
$$

dengan, $g_{1}, g_{2}$ dan $g_{3}$ adalah syarat awal dan syarat batas $(11-13)$ dan $\|.\|_{\infty}$ adalah norm $l_{\infty}$.

\section{Teorema 4. Kekonsistenan}

Skema diskretisasi (26) konsisten.

Teorema ekuivalensi Lax menyatakan bahwa metode beda hingga konsisten untuk masalah nilai awal yang diberikan (Strikwerda, 1989).

\section{Teorema 5. Kekonvergenan}

Skema diskretisasi (26) konvergen ke solusi (4) dengan syarat batas (11) - (13) sebagai $(h, \Delta \tau) \rightarrow 0$.

Bukti:

Barles (1997) membuktikan bahwa jika suatu diksretisasi dari PDP taklinear orde-2 yang konsisten, stabil dan monoton, maka konvergen ke solusi. Karena diksretisasi (26) terbukti konsisten, stabil dan monoton, maka diskretisasi (26) konvergen. Teorema 5 merupakan akibat dari teorema 2, 3 dan 4 . 
Volume 02 Nomor 022020 : page 1-22 p-ISSN: 2686-262X e-ISSN : 2685-9300 DOI : 10.24256

\section{Simulasi Numerik}

Pada bagian ini akan disajikan hasil pendekatan numerik dari empat jenis harga opsi tipe Eropauntuk melihat perilaku dan kekonvergenandari metode beda hingga upwindbaik dengan skema ekplisit maupin eksplisit. Di simulasi numerik ini akan ditentukan derajat kekonvergenan dari metode iteratif untuk penyelesaian persamaan taklinear dengan memilih serangkaian mesh yang dibangkitkan dengan membagi-dua parameter mesh pada iterasi sebelumnya.

a) Opsi Call

1. Perhitungan harga opsiCall menggunakan parameter $r=0.1, \sigma_{0}=0.2, T=1, K=40$, $S_{\text {max }}=80, k=0.01, \delta t=0.02, M=20$ dan $N=40$. Perbandingan skema eksplisit dan implisit bisa dilihat pada gambar berikut

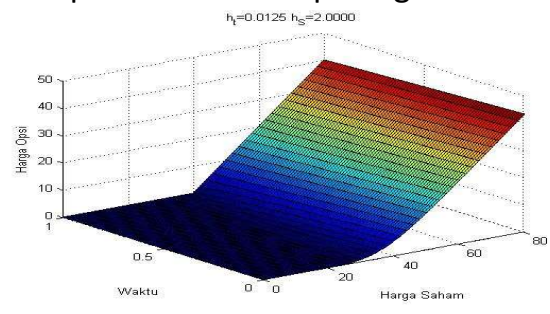

(a)

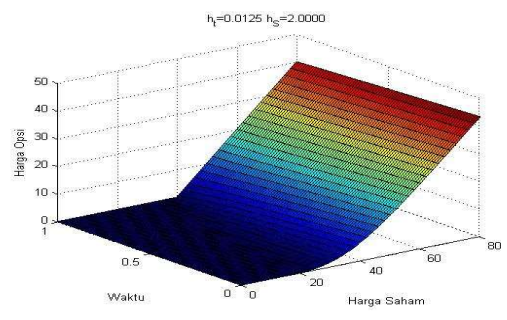

(b)

Gambar 1 Harga dari opsi CallEropa untuk posisi sebagai pembeli opsi dengan, (a) Skema eksplisit dan (b) Skema Implisit.

2. Perhitungan harga opsi Call menggunakan parameter $r=0.1, \sigma_{0}=0.2, T=1, K=$ $40, S_{\max }=80, k=0.01, \delta t=0.02, M=80 \operatorname{dan} N=160$.

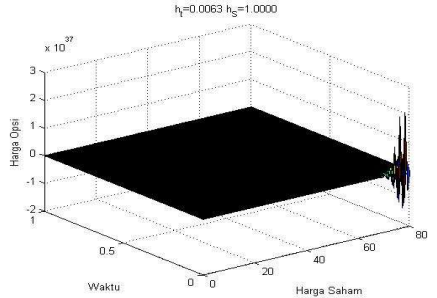

(a)

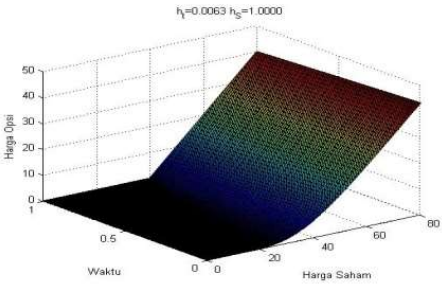

(b)

Gambar 2 Harga dari opsiCallEropa untuk posisi sebagai pembeli opsi dengan, (a) Skema eksplisit dan (b) Skema Implisit.

b) Opsi Put

1. Perhitungan harga opsiPut menggunakan parameter $r=0.1, \sigma_{0}=0.2, T=1, K=$ $40, S_{\max }=80, k=0.01, \delta t=0.02, M=20$ dan $N=40$. Perbandingan skema eksplisit dan implisit bisa dilihat pada gambar berikut
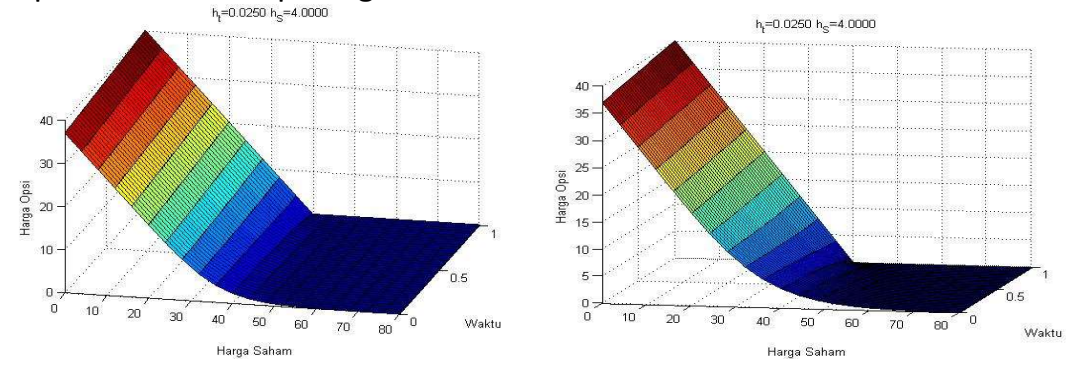
Volume 02 Nomor 022020 : page 1-22 p-ISSN: 2686-262X e-ISSN : 2685-9300 DOI : 10.24256

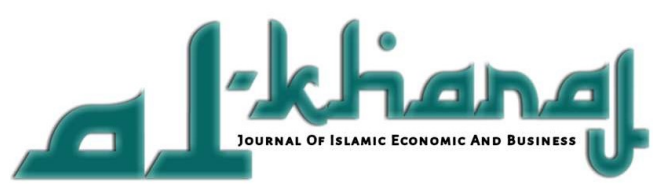

(a)

(b)

Gambar 3 Harga dari opsi Put Eropa untuk posisi sebagai pembeli opsi dengan, (a) Skema eksplisit dan (b) Skema Implisit.

2. Perhitungan harga opsiPut menggunakan parameter $r=0.1, \sigma_{0}=0,2, T=1, K=$ $40, S_{\max }=80, k=0.01, \delta t=0.02, M=20$ dan $N=40$. Perbandingan skema eksplisit dan implisit bisa dilihat pada gambar berikut

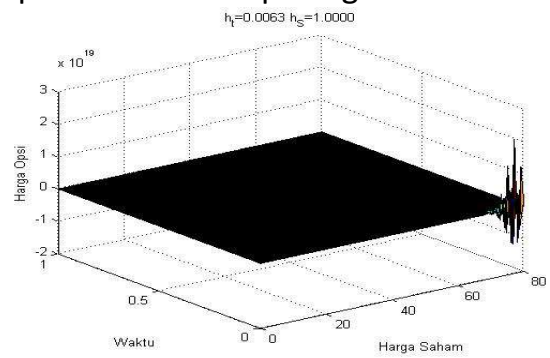

Skema eksplisit

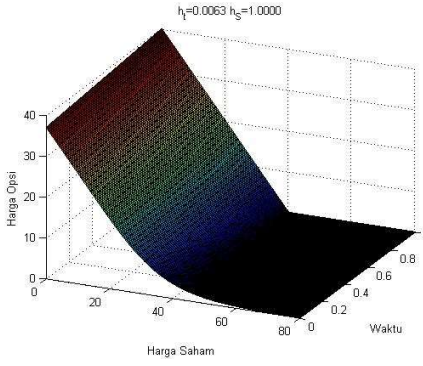

Skema Implisit

Gambar 4 Harga dari opsi Put Eropa untuk posisi sebagai pembeli opsi dengan, (a) Skema eksplisit dan (b) Skema Implisit.

c) Opsi Cash or Nothing

1. Perhitungan harga opsiCash or Nothing menggunakan parameter $r=0,1, \sigma_{0}=0,2, T=1$, $K=40, S_{\max }=80, k=0.01, \delta t=0.02, M=20$ dan $N=40$. Perbandingan skema eksplisit dan implisit bisa dilihat pada gambar berikut.

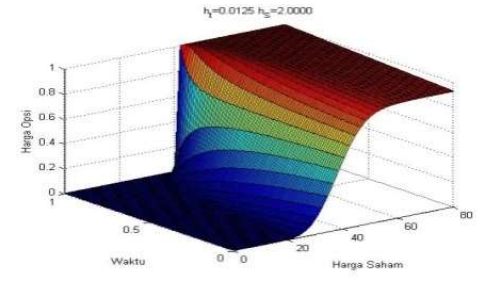

(a)

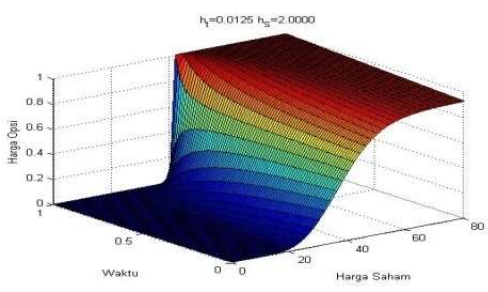

(b)

Gambar 5Harga dari opsi Cash or Nothing Eropa untuk posisi sebagai pembeli opsi dengan,

(a) Skema eksplisit dan (b) Skema Implisit.

d) Opsi Butterfly

1. Perhitungan harga opsiButterfly menggunakan parameter $r=0.1, \sigma_{0}=0.2, T=1, K=$ $40, S_{\max }=80, k=0.01, \delta t=0.02, M=20$ dan $N=40$. Perbandingan skema eksplisit dan implisit bisa dilihat pada gambar berikut.

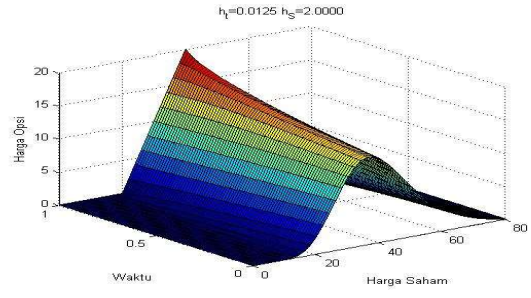

(a)

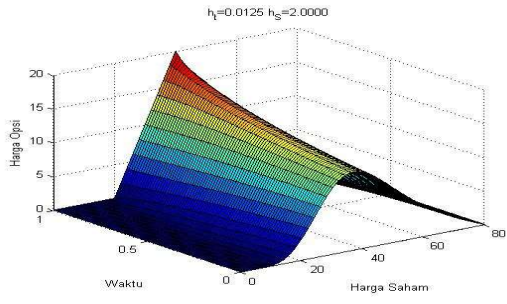

(b)

Gambar 6 Harga dari opsi Butterfly Eropa untuk posisi sebagai pembeli opsi dengan, (a) Skema eksplisit dan (b) Skema Implisit.

Dari gambar dapat kita lihat pada saat $\mathrm{M}=20$ dan $\mathrm{N}=40$ hasil yang diperlihatkan metode eksplisit dan implisit tidak jauh berbeda. Namun ketika $\mathrm{M}=80$ dan $\mathrm{N}=160$ perbedaan yang 
terjadi antara kedua metode tersebut sangat signifikan, hal ini di sebabkan karna metode ekplisit tdak stabil sehingga polanya tidak beraturan untuk partisi yang lebih besar.

Selanjutnya akan dihitung orde kekonvergenan metode tersebut dengan membandingkan solusi eksaknya. Dimana dalam menghitung orde kekonverenan metode tersebut, dipilih serangkaian mesh yang dibangkitkan secara berurutan dengan membagidua ukuran mesh sebelumnya. Karena solusi eksak tidak diketahui, maka digunakan solusi numerik dari mesh seragam dengan $h=0.03125, M=2560$ dan $\Delta \tau=0.00078125, N=1280$ sebagai solusi eksak, $V_{e k s a k}$. Selanjutnya dengan menggunakan solusi eksak tersebut, dihitung ratio dari solusi numerik dari mesh yang berurutan dengan

$$
\text { Ratio }=\frac{\left\|\mathrm{V}_{\mathrm{h}}^{\Delta \tau}-\mathrm{V}_{\text {eksak }}\right\|_{\mathrm{h}, \infty}}{\left\|\mathrm{V}_{\mathrm{h} / 2}^{\Delta \tau / 2}-\mathrm{V}_{\text {eksak }}\right\|_{\mathrm{h}, \infty}}
$$

Dimana $V_{h}^{\Delta \tau}$ adalah solusi pada mesh dengan $h$ ukuran mesh saham dan $\Delta \tau$ ukuran mesh waktu, serta

$$
\left\|V_{h}^{\Delta \tau}-V_{\text {eksak }}\right\|_{h, \infty}:=\max _{1 \leq i \leq M ; 1 \leq n \leq N}\left|V_{i}^{n}-V_{\text {eksak }}\left(S_{i}, \tau_{n}\right)\right| .
$$

Untuk orde kekonvergenan metode numeriknya dihitung dengan

$$
\text { Orde }=\text { rata }- \text { rata ratio }
$$

Tabel 1 Hasil perhitungan orde kekonvergenanSkema implisit untuk opsi Calldan opsi Put

\begin{tabular}{cccccc}
\hline \multirow{2}{*}{$\mathrm{M}$} & \multirow{2}{*}{$\mathrm{N}$} & \multicolumn{2}{c}{ Opsi Call } & \multicolumn{2}{c}{ Opsi Put } \\
\cline { 3 - 6 } & & $\|\cdot\|_{h, \infty}$ & Ratio & $\|_{h, \infty}$ & Ratio \\
\hline 10 & 5 & 0.6848 & & 0.6798 & \\
20 & 10 & 0.3821 & 1.79 & 0.3808 & 1.79 \\
40 & 20 & 0.2121 & 1.80 & 0.2118 & 1.80 \\
80 & 40 & 0.1219 & 1.74 & 0.1218 & 1.74 \\
160 & 80 & 0.0730 & 1.67 & 0.0729 & 1.67 \\
320 & 160 & 0.0442 & 1.65 & 0.0442 & 1.65 \\
640 & 320 & 0.0253 & 1.75 & 0.0253 & 1.75 \\
1280 & 640 & 0.0114 & 2.22 & 0.0114 & 2.23 \\
\hline
\end{tabular}

Hasil perhitungan ratio di Tabell menunjukkan orde kekonvergenan metode upwind pada opsi Call dan opsi Put adalah sekitar1.80.

Tabel 2 Hasil perhitungan orde kekonvergenanSkema implisit untuk opsi Cash or Nothing dan opsi Butterfly

\begin{tabular}{cclccc}
\hline \multirow{2}{*}{$\mathrm{M}$} & \multirow{2}{*}{$\mathrm{N}$} & \multicolumn{2}{c}{ Opsi Cash or Nothing } & \multicolumn{2}{c}{ Opsi Butterfly } \\
\cline { 3 - 6 } & \multicolumn{1}{c}{$\|.\|_{h, \infty}$} & Ratio & \multicolumn{1}{c}{\|\|$_{h, \infty}$} & Ratio \\
\hline 10 & 5 & 0.4013 & & 1.2637 & \\
20 & 10 & 0.3326 & 1.21 & 0.7017 & 1.80 \\
40 & 20 & 0.2594 & 1.28 & 0.3866 & 1.82 \\
80 & 40 & 0.1922 & 1.35 & 0.2142 & 1.80 \\
160 & 80 & 0.1438 & 1.34 & 0.1223 & 1.75 \\
320 & 160 & 0.1155 & 1.25 & 0.0712 & 1.72 \\
640 & 320 & 0.0852 & 1.36 & 0.0398 & 1.79 \\
1280 & 640 & 0.0512 & 1.66 & 0.0176 & 2.26 \\
\hline
\end{tabular}


Hasil perhitungan ratio di Tabel2 menunjukkan orde kekonvergenan metode upwind pada opsi Cash or Nothing adalah sekitar 1.35 dan pada opsi Butterfly adalah sekitar1.84 .

\section{KESIMPULAN / CONCLUSION}

Pada penelitian ini dapat terlihat bahwa penggunaan metode beda hingga upwind akan konvergen ketika menggunakan skema diskretisasi implisit terhadap waktu. di mana skema diskretisasi ini terbukti monoton, konsisten dan stabil. Sedangkan penggunaan diskretisasi ekplisit terhadap waktu terbukti tidak stabil sehingga tidak konvergen.

Berdasarkan hasil dari simulasi numerik, dapat ditunjukkan bahwa orde kekonvergenan untuk metode beda hingga upwind dengan model volatilitas leland adalah sekitar 1.80 untuk opsi Call, 1.80untuk opsi Put, 1.35 opsi Cash or Nothing, serta 1.84 untuk opsi Butterfly. 


\section{DAFTAR PUSTAKA / REFERENCES}

Ankudinova J. and M. Ehrhardt. 2008. The numerical solution of nonlinear Black-Scholes equations. Computers and Mathematics with Applications.

Bodie Z. Kane A. Marcus AJ. 2002. Investments. Ed ke-3. New Jersey: Prentice Hall.

Barles G. 1997. Convergence of numerical schemes for degenerate parabolic equation arising in finance, in: L.C.G. Rogers, D. Talay (Eds.), Numerical Methods in Finance. Cambridge University Press. Cambridge.

Black F \&Scholes M. 1973. The Pricing of Option and Corporate Liabilities. J. Polit. Econ.

Hull J. White A. 2006. Option. Future. and Other Derivatives. 8th edition. New Jersey: Prentice - Hall.

Hull J. White A. 1987. The pricing of option on asset with stochastic volatilities.J. Finance. 42:281-300.

Leland H. E. 1985. Option pricing and replication with transaction costs. Journal of finance.

Lesmana DC\& WangS. 2013. An upwind finite difference for a nonlinear Black-Scholes equation governing European option valuation under transaction costs. Journal of applied mathematics and computation.

Niwiga DB. 2005. Numerical method for valuation of financial derivatives. [Thesis]. South Africa : University of Werstern Cape.

Strikwerda JC.1989. Finite difference schemes and partial differential Equation (1 st ed.). chapman \& Hall. 